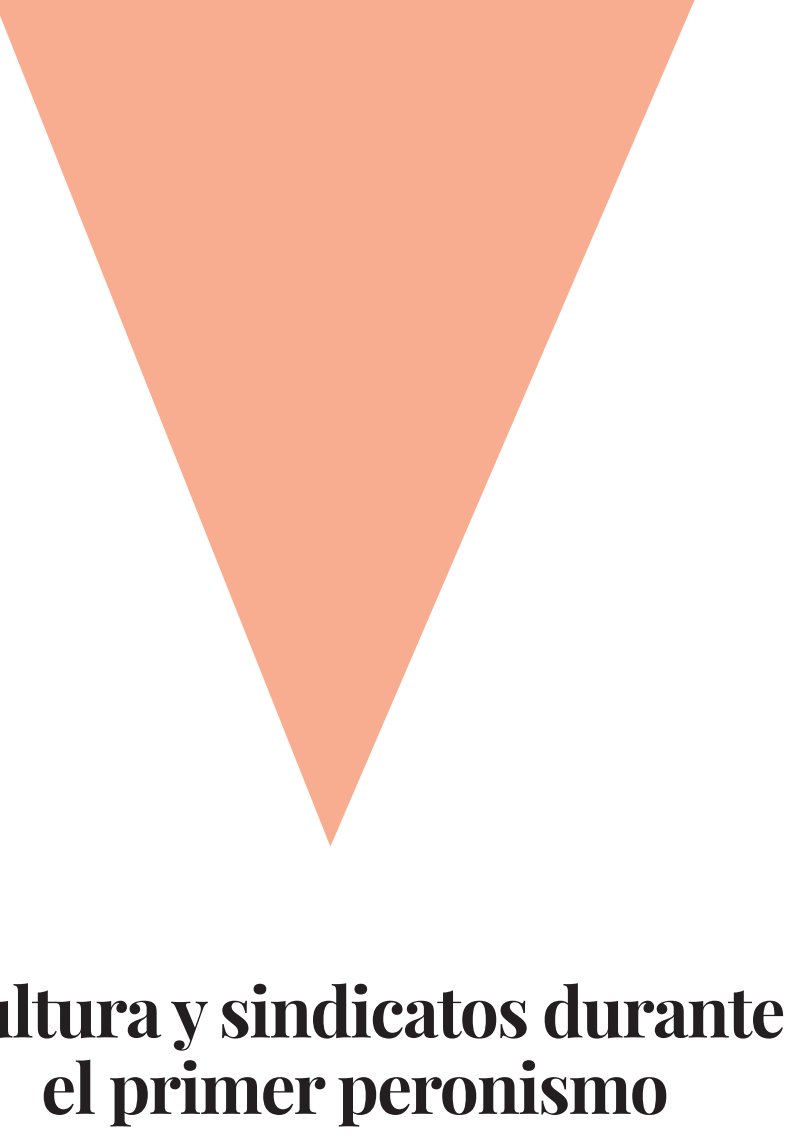

\title{
Cultura y sindicatos durante el primer peronismo
}

\author{
Yanina Andrea Leonardi ${ }^{1}$
}

1 Investigadora de Carrera del Consejo Nacional de Investigaciones Científicas y Técnicas (Conicet). Doctora en Historia y Teoría de las Artes por la Universidad de Buenos Aires (UBA) y Profesora en Enseñanza Media y Superior en Letras por la UBA; investigadora del Instituto de Historia del Arte Argentino y Latinoamericano de la Facultad de Filosofía y Letras de la UBA. E-mail: yaninaleonardi@gmail.com. 


\section{RESUMEN}

En el presente artículo se propone estudiar la planificación cultural llevada a cabo por la Confederación General del Trabajo (CGT) durante el primer peronismo (1946-1955). Esta entidad fue quien articuló los lineamientos oficiales en materia cultural ideando un plan que promovía la formación y modernización del movimiento obrero. Por estos años, la CGT en tanto entidad mediadora entre el Estado y los trabajadores postuló en su proyecto cultural la educación, el esparcimiento y la capacitación como sus núcleos centrales, complementando así el objetivo de la inserción social propuesto por la planificación nacional. El estudio se centra en las actividades, prácticas y formaciones que lo integraban, a la vez que en el personal técnico interviniente en su ejecución.

Palabras clave: Cultura. Obreros. Sindicatos. Peronismo.

\section{ABSTRACT}

The present article proposes to study the cultural planning carried out by the General Federation of the Work during the first Peronism (1946-1955). This entity was the one who articulated the official limits in cultural matter, designing a plan that was promoting the formation and modernization of the labor movement. These years, the CGT while mediating entity between the State and the workers postulated in his cultural project to the education, the scattering and the training as his central cores, complementing this way the aim of the social insertion proposed by the national planning. The study centres on the activities, practices and formations that were integrating it, simultaneously that in the technical personnel intervener in his execution.

Keywords: Culture. workers. Unions. Peronism.

\section{RESUMO}

O presente artigo propõe estudar o planejamento cultural realizado pela Confederação Geral do Trabalho (CGT) durante o primeiro período do primeiro peronismo (19461955). Essa entidade foi quem articulou as diretrizes oficiais no âmbito cultural, idealizando um plano que promovia a formação e modernização do movimento operário. Nessa época, a CGT como entidade mediadora entre o Estado e os trabalhadores postulou no seu projeto cultural a educação, o lazer e a capacitação como seus núcleos centrais, complementando assim o objetivo da inserção social proposto no planejamento nacional. O estudo enfatiza as atividades, práticas e formações que integravam a CGT, bem como a equipe técnica envolvida na sua execução.

Palavras-chave: Cultura. Operários. Sindicatos. Peronismo. 


\section{INTRODUCCIÓN}

Uno de los acontecimientos notables que presenta el período 19461955 -durante los dos mandatos de gobierno de Juan Domingo Perón- es la incursión de las políticas públicas en la esfera cultural, a partir de la concreción de un proyecto de gran complejidad que en algunos casos tuvo a los obreros como receptores o productores exclusivos del mismo. Se interpeló a ese cuerpo social desde distintas entidades, con fines netamente educativos e instructivos. Entre ellas, la Confederación General del Trabajo (CGT) fue quien articuló los lineamientos oficiales en materia cultural, ideando un plan que promovía la formación y modernización del movimiento obrero, que se ejecutaba con asiduidad mediante la labor de distintas formaciones. Entonces, la CGT, en tanto entidad mediadora entre el Estado y los trabajadores, postuló en su proyecto cultural la educación, el esparcimiento y la capacitación como sus núcleos centrales, complementando así el objetivo de la inserción social propuesto por la planificación nacional.

El propósito de este estudio es analizar el proyecto cultural de la CGT durante el primer peronismo, las prácticas y formaciones que lo integraban, la particularidad y funcionalidad de las mismas. Consideramos que el análisis de estas experiencias nos permite en 
principio conocer aspectos no tan transitados por las investigaciones que se ocupan del movimiento obrero en la Argentina; asimismo, profundizar en las intervenciones culturales del primer peronismo en su complejidad, y en este caso puntual, desde la central obrera. Por último, sostenemos que el análisis de estas experiencias y prácticas artísticas nos permite reflexionar sobre la cultura obrera argentina, advirtiendo sus particularidades en el marco de los gobiernos de Juan Perón.

\section{LA CONFEDERACIÓN GENERAL DEL TRABAJO}

Tal como señalamos al inicio de este escrito, durante los primeros gobiernos peronistas se diseñó una planificación cultural a nivel nacional, convirtiéndose en una de las novedades del período. Dicha intervención del Estado en materia cultural debe comprenderse en un clima de época. Al respecto, Patricia Berrotarán (2004) señala que las estrategias planificadoras instaladas con fuerza, una vez culminada la Segunda Guerra Mundial, respondían a la necesidad de refundar un nuevo pacto social con la ciudadanía y a la convicción basada en que el Estado era capaz de modificar el rumbo de los fenómenos económicos y sociales. Sectores ideológicos diversos coincidían en la necesidad de asegurar la legitimidad del Estado, de sus estructuras y sus intervenciones, constituyéndose así aparatos estatales fuertes capaces de controlar el territorio, las actividades y la sociedad (BERROTARÁN, 2004, p. 15-16). Estas cuestiones estuvieron presentes en el gobierno surgido del golpe de estado del 4 de junio de 1943 y se ejecutaron durante las dos presidencias de Perón a través de los planes quinquenales. Una de las innovaciones de esta gestión era el rol central desempeñado por la planificación en la labor del Estado, determinando las líneas de acción a seguir, el organismo centralizado encargado de su articulación y el personal técnico adecuado para llevarlo a cabo.

Los alcances de la planificación también incursionaban en la esfera cultural, otro de los aspectos novedosos del período en cuestión. 
En efecto, los fundamentos de las políticas culturales del primer peronismo, donde se consideraba al arte como una herramienta pedagógica y social, tenían como objetivo la inclusión de nuevos sectores sociales hasta el momento marginados, que operarían como factores determinantes a la hora de construir un consenso en una sociedad reticente a la incorporación de las masas a la vida social, política, e incluso cultural.

Dentro de esta interpelación a las masas, se distinguió a los obreros en tanto cuerpo social específico, destinándoles algunas actividades concretas. Por ejemplo, algunos organismos oficiales, como la Secretaría de Cultura y la Subsecretaría de Informaciones del Gobierno de la Nación, eran los encargados de llevar a cabo la organización de los eventos culturales y artísticos, entre ellos, la asistencia a recitales y funciones teatrales en entidades oficiales. Estas prácticas tendrían como antecedente algunas experiencias concretadas durante la gestión de Juan D. Perón en la Secretaría de Trabajo y Previsión, donde el arte cumplía un rol social a la vez que educativo. Una vez que Perón arribó a esta dependencia, a partir del golpe de estado de junio de 1943, comenzaron a gestionarse las funciones teatrales para obreros en el Teatro Nacional de Comedia (posteriormente denominado Cervantes), o la asistencia de los mismos a conciertos en el Teatro Colón. La CGT intervenía en la organización de estos acontecimientos, que a partir de 1946 se convirtieron en un proyecto sistemático.

Asimismo, desde el Ministerio de Trabajo también se organizaron eventualmente algunas actividades artísticas destinadas a los obreros, ofreciéndoles el rol de creadores, como los certámenes de literatura $(2000 \ldots$, , 1951) o artes plásticas.

La CGT también presentaba antecedentes en su incursión en materia educativa para los trabajadores. Efectivamente, antes de la irrupción del peronismo, en 1939, se creó la Universidad Obrera Argentina, entidad que - según señalan Inés Dussel y Pablo Pineau (1955, p. 122) - planteaba a la formación sindical, cultural y técnica 
como íntimamente vinculadas, y era de absoluta y única injerencia del movimiento obrero. Posteriormente, este panorama cambió radicalmente en los primeros años de la década del 1940, cuando la CGT dirigió las demandas educativas hacia el Estado.

A partir de la sanción de la Ley 13229, el 26 de agosto de 1948, se creó la Universidad Obrera Nacional (UON), cuyo funcionamiento fue reglamentado por el decreto del Poder Ejecutivo Nacional (7/10/1952), la cual se inauguró oficialmente en marzo de 1953. Pineau (1997) observa que la UON era la Tercera etapa de los Ciclos de formación técnica dependientes de la Comisión Nacional de Aprendizaje y Orientación Profesional $(\mathrm{CNAOP})^{2}$ y que para su ingreso se requería ser egresado del Segundo Ciclo de Aprendizaje de la CNAOP o de las escuelas industriales del Estado. Además, era necesario acreditar la condición de obrero y el certificado de buena conducta. Al igual que el resto de las universidades nacionales, el gobierno de la UON era ejercido por el Rector, que debía ser un obrero argentino egresado de las escuelas sindicales ${ }^{3}$ que dependían de la CGT. Cabe señalar que la institución se encontraba asesorada por un Consejo de Coordinación Industrial con participación patronal y obrera. Es así como se concreta una institución educativa oficial de índole nacional con injerencia de la entidad gremial en su dirección.

Si bien todas las actividades y entidades mencionadas tuvieron trascendencia a la hora de pensar las problemáticas obreras en el período, es recién con el surgimiento de la planificación cultural de la CGT cuando se piensa en la cultura obrera de un modo

2 Por estos años, el Estado amplió y creó el "sistema de Educación Técnica oficial como parte de un proceso de construcción de un discurso hegemónico que recogía y articulaba procesos político-culturales más abarcativos. El mismo partía del nivel primario (cursos de preaprendizaje, misiones monotécnicas), incluía el nivel medio (escuelas-fábricas, escuelas industriales de la Nación) y llegaba hasta el nivel universitario (Universidad Obrera Nacional), gozando en su totalidad de un alto grado de autonomía respecto al sistema tradicional. (PINEAU, 1997, p. 206-207).

3 Nos referiremos a las escuelas sindicales más adelante. 
sistemático durante el primer peronismo, abordando la formación de los trabajadores desde diferentes áreas.

La CGT fue uno de los actores políticos más destacados durante el período 1945-1955, que en general desde las investigaciones se la ha restringido a un funcionamiento supeditado a la voluntad de Perón, con pérdida de toda autonomía por estos años. En este sentido, nos interesa tomar el enfoque de Gustavo Contreras (2015, p. 109-127), quien entiende las prácticas, las vinculaciones políticas y la dinámica de la institución en su complejidad, observando que "pese a un innegable proceso de burocratización y verticalismo, el movimiento obrero y la CGT, de todos modos, se mantuvieron como actores activos que manifestaron de distintas formas y sobre diversos escenarios posiciones propias y una dinámica asociativa particular".

Siguiendo esta línea de pensamiento, entendemos que el proyecto cultural de la CGT se ubica en un terreno mixto, en que, por un lado, manejó con autonomía su ejecución, diseño de actividades y formaciones, a la vez que la selección del personal técnico para llevar a cabo la empresa. Por otro lado, a la hora de definir contenidos, adhirió a los fundamentos y lineamiento de la planificación cultural estatal, convirtiéndose en la entidad elegida desde el Estado como la encargada para llevar a cabo la formación cultural de los trabajadores siguiendo al Segundo Plan Quinquenal.

Dicha mixtura no le quita trascendencia a su proyecto cultural y educativo, cuyas prácticas se caracterizaron por generar formas asociativas a la vez que establece nuevos hábitos culturales entre los trabajadores al brindarles el derecho a la recreación, al ocio y al consumo cultural, al mismo tiempo que la capacitación. En este sentido, la CGT en su accionar dirigido a un público masivo se constituyó en un actor clave a la hora de pensar la modernización cultural que se dio por esos años. 


\section{DISEÑO DEL PROYECTO CULTURAL}

En octubre de 1947, dando cumplimiento a la resolución del Congreso extraordinario dado en dicha fecha ${ }^{4}$ "cuyo espíritu era el de posibilitar por todos los medios la elevación de la cultura general del trabajador y superar muy especialmente la eficacia de los cuadros sindicales del movimiento" (ARGENTINA, 1974), la CGT organizó el Departamento de Cultura. Una de sus primeras medidas fue la creación, en marzo de 1948, de la Escuela Sindical de la CGT, que funcionaba en el antiguo edificio confederal situado en la calle Moreno 2875, de la Capital Federal. También, en ese mismo espacio, el 12 de mayo de 1948 tuvo lugar la inauguración de la Biblioteca Pública del Trabajo "María Eva Duarte de Perón”, con funcionamiento en el primer piso del edificio. Se trataba de una biblioteca especializada en el tema, contemplada a la hora de pensar la formación gremial.

Rápidamente este Departamento fue reorganizado y complejizado, y pasó a denominarse Subsecretaría de Educación y Cultura. Su competencia abarcaba diversas áreas de índole formativa. Entre ellas, las más destacadas fueron: Deporte Obrero, Medicina del Trabajo, Biblioteca, Música, Coro, Teatro, Legislación del Trabajo y Escuelas Sindicales.

Esta dependencia de la CGT tuvo a un conjunto de hombres encargados de llevar a cabo la planificación cultural que aquí nos ocupa. Estos se organizaron de la siguiente manera: José G. Espejo y Antonio Valerga ocuparon la Dirección y Subdirección, respectivamente; por otra parte, se conformación algunas asesorías técnicas artísticas, Sebastián Lombardo ocupó la de música, José María Fernández Unsaín y César Jaimes, la de teatro; la dirección de la

4 El Congreso Nacional llevado a cabo entre los días 16 y 19 de octubre de 1947, de carácter extraordinario, fue uno de los más importantes convocado por la CGT, ya sea por haber reunido más de 5 mil delegados provenientes de todo el país, como por la relevancia de los temas tratados, entre ellos, la creación de las escuelas sindicales. 
Escuela Sindical estuvo a cargo del Prof. José P. Liberal, posteriormente fue reemplazado por el Prof. Juan Lyon.

Los nombres de Fernández Unsaín ${ }^{5}$, Jaimes ${ }^{6}$ y Lombardo ${ }^{7}$ - que eran los encargados de las cuestiones artísticas - fueron recurrentes en la planificación teatral tanto a nivel nacional como bonaerense, más allá de su participación en las formaciones artísticas de la CGT. Se trataba, en los tres casos, de artistas vinculados a una cultura popular urbana o folclórica, en sintonía con los contenidos de las políticas culturales oficiales. Su origen provinciano - muy recurrente en el personal técnico elegido por el Estado en estos años -, como su inserción en una cultura nacional popular, los posicionaba en un lugar marginal dentro del campo intelectual de la época. Asimismo, nos interesa señalar que la presencia de estos agentes culturales de origen provinciano nos invita a repensar el vínculo entre los intelectuales y el peronismo desde otros parámetros que los visitados hasta la actualidad, donde asiduamente se reduce el tema a una tensión entre Perón y determinados agentes - centrales en el campo intelectual porteño - provenientes de sectores liberales y de la izquierda. Al revisar los diferentes proyectos culturales, es decir, tanto aquellos de índole estatal nacional, municipal y provincial como también los gremiales, llevados a cabo durante el periodo, nos encontramos con equipos técnicos integrados por artistas e intelectuales provenientes de posicionamientos ideológicos diversos, y con una procedencia que se aleja de una primacía porteña.

5 José María Fernández Unsaín nació en Paraná, Entre Ríos, en 1918. Fue periodista, dramaturgo, guionista y director de cine. Se desempeñó como director del Teatro Obrero de la CGT. Estuvo al frente de instituciones oficiales culturales durante el primer peronismo, como el Teatro Nacional Cervantes, o la Comisión Nacional de Cultural.

6 César Jaimes nació en Buenos Aires en 1908, pero residió en Castelar, provincia de Buenos Aires. Se dedicó a la música y al teatro. Fue autor de textos dramáticos de carácter propagandístico durante el período, como El hombre y su pueblo, representado por el Teatro Obrero de la CGT.

7 Lombardo fue director del Teatro Argentino de La Plata entre 1953 y 1955. Era músico, compositor, pianista y arreglador. Nació el 26 de mayo de 1907 en Chacabuco, provincia de Buenos Aires. Para profundizar en su gestión cf.: Cadus (2015, p. 81-107). 
El proyecto cultural diseñado y llevado a cabo por la CGT estuvo integrado por diversas actividades y formaciones, que se desarrollaron inicialmente en la Capital Federal, y luego se propagaron en las provincias. La CGT consideró la estructuración de su proyecto cultural en dos grandes áreas: una sindical - que incluía la formación técnica propiamente dicha nucleada en las Escuelas sindicales -, y otra artística y recreativa, donde se nucleaban actividades artísticas y deportivas. En su conjunto le ofrecían al obrero una capacitación integral, que también incluía aspectos recreativos, que intervenía directamente en el diseño del ocio de los mismos.

\section{LAS ESCUELAS SINDICALES}

"La realización del gran programa de recuperación nacional que orienta el General Perón en su acción de gobierno requiere la formación de una amplia conciencia sindical en las masas de trabajadores. Para tan elevado fin se crean las escuelas sindicales dependientes de los gremios. En un acto simbólico quedan inauguradas las clases en 54 establecimientos de preparación sindical. De este modo se propende a la reafirmación y defensa de los postulados de la doctrina peronista”. (ESCUELAS..., 1952, p. 34)

Desde la revista Mundo Peronista se formulaba la concreción de un objetivo: la proyección de las Escuelas sindicales a nivel nacional. Estas habían tenido su comienzo en marzo de 1948 con la Escuela Sindical de la CGT, en el edificio de la misma situado en la Capital Federal. El propósito de ellas residía no solamente en contribuir con el nivel cultural de los trabajadores, sino también formar cuadros dentro del movimiento obrero a partir de la implementación de la capacitación sindical.

En la práctica, esta entidad desarrollaba su actividad en el horario posterior a las $19 \mathrm{~h}$, es decir, en una franja horaria postlaboral. 
Según directivas de la CGT, cada sindicato debía ocuparse de esta enseñanza, y el cuerpo docente que tomase el rol de "maestro" debía provenir de la misma actividad. Por ejemplo, el cuerpo de profesores de la ES n. ${ }^{\circ} 1$ estuvo integrado por: Antonio Valerga, Mario Castelluccia, Ángela Rodríguez Nasso, Máximo Daniel Monzón, Francisco Cordúa, Héctor Barabini, Álvaro Sanjurjo, Nicanor García, Julián Belardoni, José Diéguez, Luis Juix Callis, entre otros. Para garantizar la creación y funcionamiento de las Escuelas sindicales a nivel nacional, la Subsecretaría de Cultura de la CGT contó con una comisión de representantes sindicales provenientes de distintos gremios como: Tranviarios, ATE, Aeronáuticos, Empleados de Comercio, Gráficos, Metalúrgicos, Docentes, Jaboneros, Carne, Aguay Energía, Telefónicos, Luzy Fuerza, Caucho, Taxis, Portuarios, Espectáculos Públicos, Calzado, Madereros y vendedores.

El plan de estudios de las Escuelas sindicales inicialmente estuvo integrado por dos niveles, que contemplaban la formación escolar de los asistentes. El primer nivel estaba dirigido a aquellos que no tenían certificado de estudios de sexto grado, y cuyas asignaturas eran: Lenguaje, Redacción, Historia Argentina (1810-1853), Problemas Argentinos, Organización Sindical y Legislación del Trabajo. Y el segundo nivel se destinaba a quienes contaban con el certificado de estudios primarios o estudios especializados, y estaba integrado por las siguientes asignaturas: Redacción, Historia Argentina (1853-1948), Política Económica Argentina, Sindicalismo y Medicina del Trabajo.

Como instancia superior a estos estudios, los alumnos tenían la opción de ingresar en el Curso de Elevación Cultural Superior Juan Perón $^{8}$ (BOTTARINI, 1997, p. 402), que estaba dirigido por Rodolfo Tecera del Franco, cuyas clases se llevaban a cabo en la Facultad de Derecho de la Universidad de Buenos Aires.

8 De este centro de estudios fueron seleccionados algunos trabajadores para prestar servicios en el exterior como "Agregados Obreros", tal como ya existían en países como Estados Unidos y Gran Bretaña. Al respecto cf.: BOTTARINI, 1997. 
En septiembre de 1955, fecha del derrocamiento del gobierno de Perón, estaban en funcionamiento más de 140 escuelas sindicales; 76 de ellas dependían directamente de la Subsecretaría de Cultura de la Central Obrera y se ubicaban en distintas ciudades provinciales.

\section{ARTE Y RECREACIÓN}

Si bien la CGT tuvo a su cargo la organización de actividades artísticas - como la asistencia a espectáculos musicales y teatrales realizados en instituciones oficiales-, también desarrolló formaciones que enseñaban al obrero disciplinas artísticas concretas, como el teatro, la música o el canto. Es decir, los trabajadores intervenían en la planificación de la CGT, ya sea como consumidores o productores culturales. Estas formaciones fueron las siguientes: el Teatro Obrero (1948), el Coro Obrero (1949) y la Orquesta Obrera (1952). Esta última, de creación más tardía, fue la que menos trascendencia tuvo con respecto a las anteriores. Todas tenían como propósito democratizar un patrimonio cultural entre los sectores populares, función que se destacaba en la promoción de su presentación:

"Esta es, pues, la tercera creación de carácter cultural que se realiza en su beneficio: antes lo fue el Teatro Obrero, meritorio conjunto vocacional; luego, el disciplinado Coro Obrero, y ahora la Orquesta Obrera de la CGT, con lo que se demuestra una vez más que la cultura ha dejado de ser un privilegio de las clases social o económicamente mejor colocadas" (CONQUISTAS..., 1952, p. 19).

Los contenidos culturales difundidos por las formaciones artísticas obreras coincidían con los postulados de la doctrina peronista. En este sentido, la política cultural inscribía sus bases "en el mapa de la cultura occidental y latina, a través de su vertiente hispánica”, según las reiteradas definiciones dadas por Perón (ARGENTINA, 1947) en los documentos oficiales. De este modo, el gobierno establecía su aparato cultural sobre postulados tradicionalistas, que no implicaban una actitud rupturista con el pasado, al contrario, 
retomaban valores de la cultura preexistente que serían resignificados en función del ideario peronista. Entre ellos, cobran relevancia los valores pertenecientes al cristianismo y nacionalismo. Es así como la oferta cultural del gobierno, y por extensión de la CGT, se centró en la postulación de un arte nacional en desmedro de lo foráneo, entablando cierto paralelismo entre la dependencia económica - que el peronismo cuestionaba-y la dependencia cultural. Asimismo, otra de las operaciones implementadas fue la aplicación de una "tradición selectiva" - en términos de Williams (1980)en la opción de sus contenidos, que consistió en la selección de determinadas tradiciones de representación a las que se les otorgó nuevas significaciones en el presente, tal como mencionamos recientemente. Esta práctica se tradujo en la recuperación de estéticas populares como el nativismo, el sainete, el folklore y el tango, entre otras.

Observamos que la tarea llevada a cabo por las formaciones artísticas tenía dos instancias de realización, una organizada por la CGT; y otra, por algunos gremios en particular, situados en barrios porteños y localidades provinciales. En el primer caso, generalmente se trataba de eventos de gran magnitud que tenían protagonismo en las festividades nacionales o pertenecientes a la liturgia peronista. En cambio, en el caso de los gremios, se trataba de una labor cotidiana inserta en un espacio comunitario, donde el obrero encontraba en su ámbito laboral una oferta de actividades que podía realizar junto a sus compañeros en un tiempo externo al del trabajo. En ambos casos, se constituían ámbitos donde comulgaban la educación con el esparcimiento, el trabajo colectivo con el arte y las ideas políticas.

El Teatro Obrero de la CGT fue la primera formación artística que integró esta planificación. Creado en 1948, fue dirigido por José María Fernández Unsaín, y codirigido por César Jaimes. El funcionamiento del elenco residía en la reunión de obreros pertenecientes a distintos gremios, que después de su jornada laboral concurrían 
a los ensayos y clases formativas que estaban a cargo de las autoridades del grupo. El estreno de las producciones del Teatro Obrero se realizaba generalmente en el Teatro Nacional Cervantes, con la presencia - en la mayoría de los casos - del Presidente y la Primera Dama, al igual que de otras autoridades nacionales o municipales. Posteriormente, el elenco iniciaba una gira que comprendía la realización de funciones en las salas barriales de la Capital Federal y el conurbano, y en los teatros más representativos de las ciudades provinciales. En una segunda etapa, coincidente con la mayor centralidad que le otorgaba al teatro el "Segundo Plan Quinquenal", se formaron nuevos elencos obreros en el resto del país, que adoptaban la misma metodología de funcionamiento que el grupo inicial. El repertorio del Teatro Obrero de la CGT estuvo integrado por piezas nativistas como Hacia las cumbres y Cuando muere el día, ambas pertenecientes a Belisario Roldán, La isla de don Quijote y Se dio vuelta la casa, ambas de Claudio Martínez Payva, Madre tierra y La nueva fuerza, las dos de Alejandro Berruti, sainetes como Mateo, de Armando Discépolo, y clásicos universales como el Médico a palos, de Molière, en versión de Pedro Escudero. Además, se incluyeron piezas escritas especialmente para el elenco, afines al ideario peronista, sumándose al teatro de propaganda, que potenciaban el carácter nacional del corpus (LEONARDI, 2012).

En 1949, la CGT creó el Coro Obrero, formación de carácter mixto, que pretendía congregar a trabajadores de diversas tareas (PARA EL..., 1951). En las fuentes consultadas, no consta quien desempeñaba el rol de la dirección. Pensamos que posiblemente Sebastián Lombardo pudo haber cumplido esa función en tanto que "Asesor Técnico en música” del proyecto cultural de la CGT.

La estructura de funcionamiento de esta formación era similar a la del Teatro Obrero: se estudiaba y ensayaba en un horario externo a la jornada laboral, con un grupo integrado por obreros y obreras de diversos gremios. Si bien inicialmente se formó el grupo dependiente de la CGT, después, y como consecuencia del accionar de la 
planificación cultural que la entidad encabezada, se crearon formaciones menores en gremios de localidades provinciales, que actuaban tanto en los eventos de su comunidad como en otros lugares.

En 1951, la formación central del Coro Obrero ya estaba constituida, pero como las autoridades de la CGT pretendían que se llegara a congregar tres mil voces, se llevó a cabo la reapertura de la inscripción. En respuesta a los lineamientos de los contenidos de las políticas culturales oficiales, el repertorio de este coro tenía un carácter predominantemente nacional y folclórico, incorporando canciones como "Alborada", "La Criolla", "La Media Caña”, trozos de la ópera El Matrero y otras pertenecientes al cancionero autóctono. Al mismo tiempo, se agregaba un repertorio de carácter político que integraba la liturgia peronista: en cada una de sus presentaciones el Coro Obrero interpretaba la "Marcha de la CGT", "Los muchachos peronistas" y "Evita Capitana".

En cierto modo, la actuación del Coro Obrero estaba más estrechamente vinculada a los eventos organizados directamente por la CGT, que la del Teatro Obrero, cuyas presentaciones cobraban cierta autonomía. Ciertamente, el desempeño artístico de esta formación coral fue una de las atracciones que integraban los eventos celebratorios en los que la CGT participaba. Estos eran el $1^{\circ}$ de Mayo, Día de los Trabajadores, en que la CGT tenía la organización total del evento; y el 17 de Octubre, Día de la Lealtad, en que intervenía con algunas actividades en particular.

Ambos acontecimientos formaban lo que podríamos denominar como las "fiestas peronistas" constituidas por celebraciones por medio de eventos de gran espectacularidad y la ocupación masiva del espacio público. Su fin era celebrar comunitariamente los logros obtenidos por los trabajadores durante los años de gestión peronista. En este proceso de "peronización" de las fechas conmemorativas ${ }^{9}$, el $1^{\circ}$ de Mayo resultó seguramente el más afectado, ya que la celebración de esta fecha creció notablemente, sistematizándose

9 Cf. Plotkin, 2007. 
y complejizándose debido a la intervención del Estado y la participación masiva de los sectores populares. Efectivamente, durante el primer peronismo, muchas fechas patrias devinieron en celebraciones de gran espectacularidad, conformadas por intervenciones artísticas diversas, despliegue escenográfico, y la ocupación del espacio público como uno de sus elementos centrales. Allí confluían cruces entre espectáculo y política, característica recurrente en la época.

Si bien el carácter "festivo" del $1^{\circ}$ de Mayo es previo a la llegada del peronismo - tal como la bibliografía especializada ha señalado ${ }^{10}-$, por estos años la denominación "Fiesta del Trabajo" adquirió oficialidad y desplazó a otras anteriores. $\mathrm{Al}$ mismo tiempo, el $1^{\circ}$ de Mayo resultó una de las fechas conmemorativas más afectadas debido a la vinculación directa que se realizó en el evento con las reformas laborales implementadas por el Estado en el período. Uno de los atractivos principales, desde 1948, fue la elección de la "Reina Nacional del Trabajo" "1. Además, en ese mismo acto, se realizó el desfile de carrozas que ilustraban los Derechos del Trabajador ${ }^{12}$.

Entonces, es así que el clima festivo dejó de ser un elemento de tensión a la hora de asumir la conmemoración de la fecha, para convertirse en una fiesta "oficial" de los trabajadores, donde el arte y la cultura popular jugaron un rol central en la interpelación a los sectores populares. Asimismo, el gran despliegue artístico que se desarrollaba en el espacio público creaba un clima de armonía, contraponiéndose así a las escenas de confrontación vividas por los trabajadores en el pasado.

10 Leandro García (2014) señala que, en la etapa previa a la irrupción del peronismo, se registran algunos eventos festivos en las conmemoraciones del $1^{\circ}$ de Mayo realizadas en algunas localidades provinciales.

11 Cf. Lobato, 2005.

12 "En virtud de que las características del festejo requerían de un espacio más amplio que la Plaza de Mayo, el acto oficial se desarrolló en 9 de Julio y Moreno: diez carrozas decoradas con alegorías de los 'derechos' realizadas en papel maché desfilaron solemnemente cuando finalizaron los discursos" (GENE, 2005, p. 100). 
El Coro Obrero de la CGT participó reiteradamente en este evento, teniendo a su cargo la interpretación del Himno Nacional, y luego de la pronunciación de los discursos por parte de Perón, de Eva y del Secretario Gral. José Espejo, de las marchas peronistas mencionadas anteriormente.

El otro evento inserto en la liturgia peronista, en el que esta formación coral tenía participación, era el 17 de Octubre. Concretamente, en los festejos de 1951, el Coro Obrero de la CGT integró la programación artística de la Semana de la Lealtad, presentándose en el Teatro Colón. Este evento -que fue presenciado por autoridades gubernamentales como el Presidente y su esposa, el Ministro del Trabajo, José María Freyre, el Director Nacional de Cultura, José María Castiñeira de Dios y el Secretario General de la central obrera, José Espejo- pretendía constituirse en un espectáculo de jerarquía, que reunía los elementos más trascendentes de la planificación oficial: un grupo de artistas obreros que accedían al arte a raíz de la intervención de la políticas públicas, haciendo uso de uno de los espacios más elitistas de la cultura argentina, como el Teatro Colón. Es decir, un claro gesto de democratización del patrimonio cultural, al que se sumaba la interpretación de un repertorio nacional.

Esta apropiación de los espacios y de los bienes culturales por parte de los trabajadores se hizo presente en el discurso del secretario gremial:

Le sucedió el señor Espejo, quien destacó la feliz circunstancia de que un coro obrero actuara en el Colón, hoy accesible a los hombres de condición humilde. Agregó que, lograda la humanización del capital, se persigue también la humanización de la cultura que, como todos los bienes sociales, tiene sentido si se la aproxima al hombre para que sirva del medio de perfección y de felicidad. (EL CORO..., 1951)

Sin embargo, la presencia de los obreros en el Teatro Colón - en tanto espacio paradigmático de la alta cultura - no generó una real 
democratización de este ámbito en el período posterior al derrocamiento del peronismo, convirtiéndose en una experiencia aislada dada solamente en este período, que generaba reacciones adversas en el público habitual de la sala.

\section{ALGUNAS CONSIDERACIONES A MODO DE CONCLUSIÓN}

A lo largo de este trabajo intentamos aproximarnos al proyecto cultural de la CGT, que tuvo como fin la formación cultural y sindical de la clase obrera. Analizamos la conformación de las Escuelas Sindicales y dos de las formaciones artísticas ${ }^{13}$ de intervención política llevadas a cabo por la CGT durante el primer peronismo, así como intentamos conocer la particularidad y funcionalidad de las mismas al igual que el proyecto cultural en el que estaban insertas. Todas estas formaciones y actividades se constituyeron en los instrumentos que integraron en ese período una cultura obrera, entendida como el desarrollo de formas asociativas y hábitos ligados a la instrucción y a la recreación de los trabajadores.

Cabe señalar que la construcción de un proyecto que reunía a los obreros, la educación, el esparcimiento y los sindicatos como elementos centrales concretaría el inicio de un proceso de modernización cultural que se sustentaba en el ingreso masivo de nuevos agentes culturales, que modificaría notablemente la estructura social del país, a la vez que contribuiría a la constitución de una nueva fuerza social que adquiriría representación en la vida política nacional.

Observamos que en el marco de la concreción de la planificación cultural oficial - que contó con objetivos claros y agentes intelectuales destinados a su ejecución -, la CGT jugó un rol considerable en la ejecución de la misma. Al respecto, debemos aclarar que el proyecto cultural del Estado desarrollado durante primer

13 Nos centramos en el Coro y el Teatro, en tanto son formaciones que cuentan con mayor disponibilidad de fuentes. En cambio, la Orquesta, que fue fundada posteriormente, no presenta información considerable que permita su reconstrucción. 
peronismo ocupó siempre un lugar marginal dentro del campo intelectual, a pesar de los reiterados intentos por lograr un mejor posicionamiento.

\section{REFERENCIAS}

2000 obreros presentes en un cotejo literario: ha sido realizado por primera vez en el país. El Líder, Buenos Aires, ano 6, 3 jun. 1951. p. 1.

BERNETTI, J.; PUIGGROS, A. (dir.). Peronismo: cultura política y educación (1945-1955). Buenos Aires: Galerna, 2006.

BERROTARÁN, P. La planificación como instrumento: políticas y organización en el Estado peronista (1946-1949). In: BERROTARAN, P.; JAUREGUI, A.; ROUGIER, M. (ed.). Sueños de bienestar en la Nueva Argentina: Estado y políticas públicas durante el peronismo 1946-1955. Buenos Aires: Imago Mundi, 2004. p. 15-45.

BOTTARINI, R. Estrategias-educativas peronistas: el caso de los agregados obreros. In: CUCUZZA, H. Estudios de historia de la educación durante el primer peronismo 1943-1955. Buenos Aires: Los Libros del Riel, 1997. p. 401-445.

CADUS, M. E. El Teatro Argentino de La Plata. In: LEONARDI, Y. (dir.). Teatro y Cultura durante el primer peronismo en la provincia de Buenos Aires. La Plata: Archivo Histórico de la Provincia, 2015. p. 81-107.

CONQUISTAS culturales del obrero. Mundo Peronista, Buenos Aires, ano 1, n. 17, mar. 1952. Calendario del Justicialismo, p. 19.

CONTRERAS, G. ¿Apéndice estatal? La CGT durante el primer gobierno peronista: asociaciones, funcionamiento institucional y proyecciones políticas (1946-1955). In: ACHA, O.; QUIROGA, N. (coord.).

Asociaciones y política en la Argentina del siglo veinte. Entre prácticas y expectativas. Buenos Aires: Prometeo, 2015. p. 109-127.

CUCUZZA, H. (dir.). Estudios de historia de la educación durante el primer peronismo 1943-1955. Buenos Aires: Los Libros del Riel, 1997.

DUSSEL, I.; PINEAU, P. De cuando la clase obrera entró al paraíso: la educación técnica estatal en el primer peronismo. In: PUIGGROS, A. (dir.). Discursos pedagógicos e imaginario social en el peronismo (1945-1955). Buenos Aires: Galerna, 1995. p. 107-176. 
EL CORO obrero actuó anoche en el T. Colón. La Razón, Buenos Aires, ano 47, 14 out. 1951, p. 3-4.

ESCUELAS Sindicales. Mundo Peronista, Buenos Aires, ano 1, n. 20, maio 1952. Calendario del Justicialismo, p. 34.

GARCIA, L. La conmemoración del Primero de Mayo como reafirmación de la identidad obrera en la CGT sindicalista, 1930-1935. In: BISSO,

A.; KAHAN, E.; SESSA, L. (Ed.), Formas políticas de celebrary conmemorar el pasado (1930-1943). La Plata: Ceraunia, 2014. p. 43-59.

GENE, M. Política y espectáculo: los festivales del primer peronismo: el 17 de octubre de 1950. In: Arte y recepción; Jrnadas de Teoría e Histori de las Artes del Caía, 7. 1997, Buenos Aires. Anales [...]. Buenos Aires: Caia, 1997. p. 185-192.

GENE, M. Un mundo feliz: imágenes de los trabajadores en el primer peronismo 1946-1955. Buenos Aires: FCE, 2005.

LEONARDI, Y. Experiencias artístico-educativas para los obreros durante el primer peronismo. In: Nuevo Mundo Mundos Nuevos, Paris, p. 1-13, 11 jul. 2012. DOI: https://doi.org/10.4000/nuevomundo.63699. Disponível em: https://bit.ly/2QXJVfu. Acesso em: 22 maio 2015.

LOBATO, M. (ed.) Cuando las mujeres reinaban: belleza, virtud y poder en la Argentina del siglo XX. Buenos Aires: Biblos, 2005.

PARA el Coro de la CGT reabren la inscripción. EL Líder, Buenos Aires, ano 6, 6 jun. 1951. p. 4.

PINEAU, P. De zoológicos y carnavales: las interpretaciones sobre la Universidad Obrera Nacional. In: CUCUZZA, H. (dir.). Estudios de Historia de la Educación durante el primer peronismo 1943-1955. Buenos Aires: Los Libros del Riel, 1997. p. 205-227.

PLOTKIN, M. El día que se inventó el peronismo: la construcción del 17 de octubre. Buenos Aires: Sudamericana, 2007.

WILLIAMS, R. Marxismo y literatura. Barcelona: Península, 1980.

\section{FUENTES}

ARGENTINA. Presidencia de la Nación. Subsecretaría de Informaciones. Dirección General de Prensa. Exposición del General Perón sobre la política cultural del estado, ante la delegación de intelectuales que lo visitara. Subsecretaria de Informaciones: Buenos Aires, 13 nov. 1947. 
ARGENTINA. Presidencia de la Nación. Subsecretaría de Informaciones. Segundo Plan Quinquenal. Subsecretaría de Informaciones: Buenos Aires, 1953.

ARGENTINA. Secretaria de Cultural. Instituto de capacitación sindical. Sindicato de Luz y Fuerza. Educación Sindical: apuntes para trabajar. Buenos Aires: Instituto de capacitación sindical, 1974.

CRÍTICA. Buenos Aires: [s.n.], 1913-1962.

EL LÍDER. Buenos Aires: [s.n.], 1946-1955.

LA RAZÓN. Buenos Aires: [s.n.], 1905-1990.

REVISTA MUNDO PERONISTA. Buenos Aires: Ed. Haynes, 1951-1955. 